\title{
Erratum: Origins of overshoots in the exciton spin dynamics in semiconductors
} [Phys. Rev. B 99, 165308 (2019)]

F. Ungar, M. Cygorek, and V. M. Axt

(Q) (Received 1 July 2019; published 12 July 2019)

DOI: 10.1103/PhysRevB.100.049902

The width of the broadened $\delta$-function $\delta_{\omega, 0}^{b}=\frac{1}{\sqrt{\pi} w_{\mathrm{b}}} \exp \left[-\left(\hbar \omega / 2 w_{\mathrm{b}}\right)^{2}\right]$ in Eq. (2) should read $w_{\mathrm{b}}=1 \mu \mathrm{eV}$. 